\title{
RUST INCIDENCE AND HEADING OF OVERSEAS RYEGRASS CULTIVARS IN NEW ZEALAND
}

\author{
C. S. Armstrong and W. Rumball \\ Grasslands Division, DSIR, Palmerston North
}

\section{Abstract}

Spaced plant data on rust and heading are summarized, comparing overseas ryegrass cultivars with those of Ncw Zealand. Relative to 'Grasslands Ruanui' perennial ryegrass, most overseas cultivars were equally or more resistant to field infections of rust, and tended to be later heading. Overseas cultivars of annual ryegrasses tended to be earlier heading than 'Grasslands Paroa' Italian ryegrass.

\section{INTRODUCTION}

AN EARLIER PAPER (Rumba11 and Armstrong, 1974) has compared in this country the seasonal growth of 143 overseas ryegrass cultivars with New Zealand certified ryegrasses. It showed the latter to be usually much superior, especially among the perennial cultivars.

In this paper other characteristics related to seasonal growth are compared. The first of these is disease. Jn terms of lowered productivity and lowered acceptability to grazing animals, the most serious disease in New Zealand affecting ryegrass is almost certainly crown rust (Puccinta coronata Corda). Lancashire and Latch (1966) showed that rust infection could seduce by more than half the green leaf yield of 'Grasslands Ruanui' perennial ryegrass at certain periods in summer. Corkill (1956) reported that strongly rusted ryegrass plants were not readily grazed by sheep, indicating that even the available green leaf would be poorly utilized. A further effect of crown rust is a weakening of the ryegrass component of a mixed sward to the extent of allowing strong clover dominance (Lancashire and Latch, 1970). These last two factors are not directly associated with ryegrass seasonal growth, and not implicit in the data of the earlier paper (Rumba11 and Armstrong, 1974). It is therefore important to record separately the relative resistance to rust of overseas ryegrasses, with the possibility of future breeding leading to a greater degree of resistance in New Zealand cultivars. 
A second feature of possible agronomic importance in ryegrass is lateness of heading. As the seasonal growth peak of 'ryegrass closely precedes its heading peak, late heading coltivars could therefore potentially provide feed of better quality later into the summer, and be of value in a region such as Southland for lamb "finishing", although McLeod (1974) and unpublished MAF reports showed only minor and inconsistent differences in pasture yield and growth rates of lambs grazing on late-heading ryegrass. Nevertheless, the relationship between heading date, amount of heading, aftermath heading, summer persistence, and autumn recovery may play an important role in breeding for conservation systems.

\section{METHODS}

Data summarized here have been obtained from the plant breeding files of Grasslands Division. They relate to spaced-plant experiments carried out over the last 35 years at Palmerston North and/or one or more of the regional stations. Further details on these experiments can be found in Rumba11 and Armstrong (1974).

Rust incidence was scored for each plant on a O-5 scale of increasing severity, generally without distinction between crown and stem rust ( $P$. graminis Pers.). Dependent upon the season, the time of scoring varied from mid-summer to mid-autumn.

Using the normal closing time for ryegrass crops in New Zealand, earliness of heading was measured in two ways: (a) By the stages of emergence of reproductive heads from their sheaths, all plants in the block being scored on a O-5 scale on the same day, and (b) by the actual date of emergence of each plant. The appearance of the first five heads was adopted as the emergence date.

\section{RESULTS}

\section{Perennial Ryegrasses}

\section{Rust}

The mean score for each overseas cultivar was calculated relative to Ruanui $=100$, for each experiment in turn. Because relative scores for any given cultivar were very consistent regardless of the year or region of the experiment, all such scores were averaged for each cultivar in turn. The overall mean is given for each cultivar in Fig. 1, grouped according to country of origin. These data involve 63 overseas cultivars, averaging ' 2.2 experiments each. 
Figure 1 shows that only $15(31 \%)$ of the overseas cultivars showed as much as or more rust infection than Ruanui. Some of these, especially those from Australia and U.K., are cultivars bred many years ago. The large number of diploid and tetraploid cultivars bred in the Netherlands are consistently more recent than Ruanui, as are the three New Zealand cultivars, 'Grasslands Nui', 'Grasslands Ariki', and the experimental tetraploid hybrid, 'Grasslands 4708'. The nine tdtraploids included in the Dutch list range from 56 to $73 \%$ (means 63\%), while the diploids range from 33 to $88 \%$ (means $71 \%$ ).

Although cultivars from some countries showed less rust infection than others, no geographic or climatic patterns were evident.

\section{Other Diseases and Pests}

Perennial ryegrass is susceptible to attack by other diseases such as leaf blight (Drechslera spp.) and by insect pestsArgentine stem weevil (Hyperodes bonariensis), grass grub (Costelytra zealandica), and white-fringed weevil (Graphognathus leucoloma). However, no conclusive evidence was obtained to show differences in susceptibility among the cultivars tested.

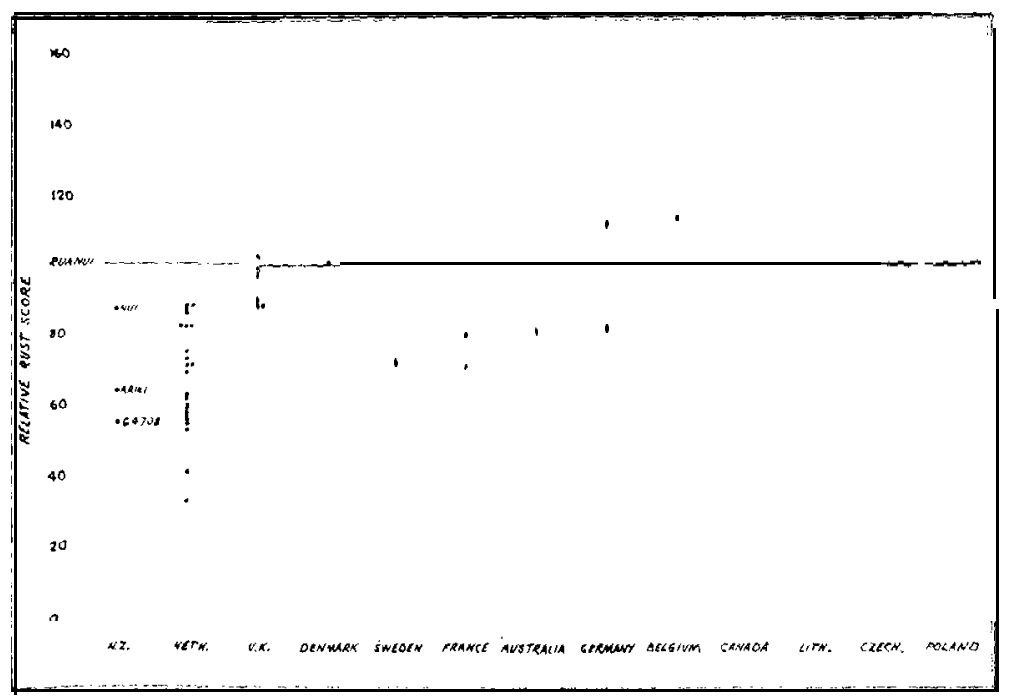

FIG. 1: Rust scows of overseas perennial ryegrasses, relative to 'Grasslands Ruanui'. (Low scores indicate low incidence of rust.) 


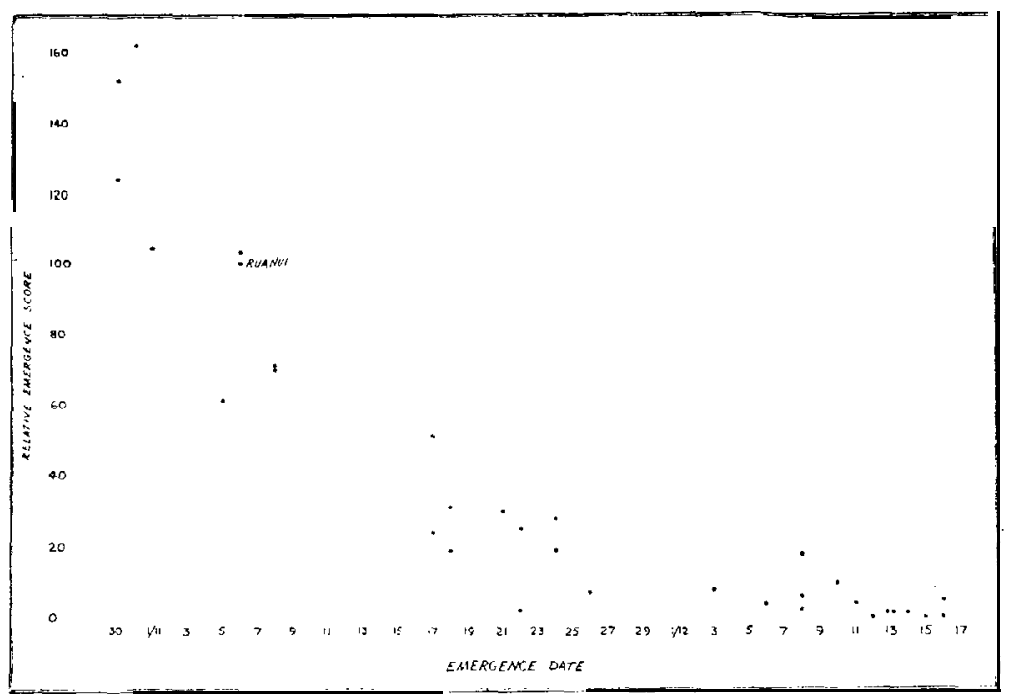

FIG. 2: Relationship between two scoring techniques for head emergence of perennial ryegrass. (a) Degree of emergence on a given date. (b) Date of emergence.

\section{H eading}

As stated earlier, two techniques were used to score for this character. Figure 2 shows the relationship between two sets of data for 33 cultivars which were scored using both methods. Once again, each cultivar score was taken as the mean for all experiments in which it appeared with Ruanui, although both methods were not always applied in the same experiment.

From late October until late November there was an apparent linear relationship. After this time, however, the scoring method failed to differentiate between cultivars with different emergence dates. This indicates an inadequacy in the system of scoring all cultivars for degree of emergence on a given day. Cultivars scoring zero on that day include a range from late to very late. Hindsight suggests that, given such a preponderance of cultivars at this end of the scale, head emergence observations on a given day should have the scale enlarged by delaying the day of scoring a sufficient time to allow the late heading group to exhibit variation in emergence, even though plants of the early heading group would be in the flowering or even seed maturation stage.

Most of the emergence data collected in past years have employed this system because of the time involved over numerous 
days in recording the actual date of emergence. Notwithstanding the scale inadequacies just shown, there is value in studying the accumulated data presented in Fig, 3.

It is shown that most overseas cultivars were later heading than Ruanui (Fig. 2). Thirteen were more than four weeks later. Cultivars from Denmark and Sweden, countries which would be expected to breed for late maturity to escape winter damage, are in this group. The few cultivars shown in Fig. 3 to be considerably earlier than Ruanui have probably been bred for conservation use.

\section{ANNUAL RYEGRASES}

There have been many fewer data collected over the years in either disease or heading characters for annual ryegrasses. Both Westerwolds and, to a lesser degree, Italian ryegrass (Lolium multiflorum Lam.) are normally utilized and dead before midsummer, when rust is most damaging.

Scorings for degree of emergence were made on a given day and are presented in Fig. 4, relative to Grasslands Paroa $=100$ (normally 13 days later than Ruanui). Included are the shortrotation hybrid ryegrasses.

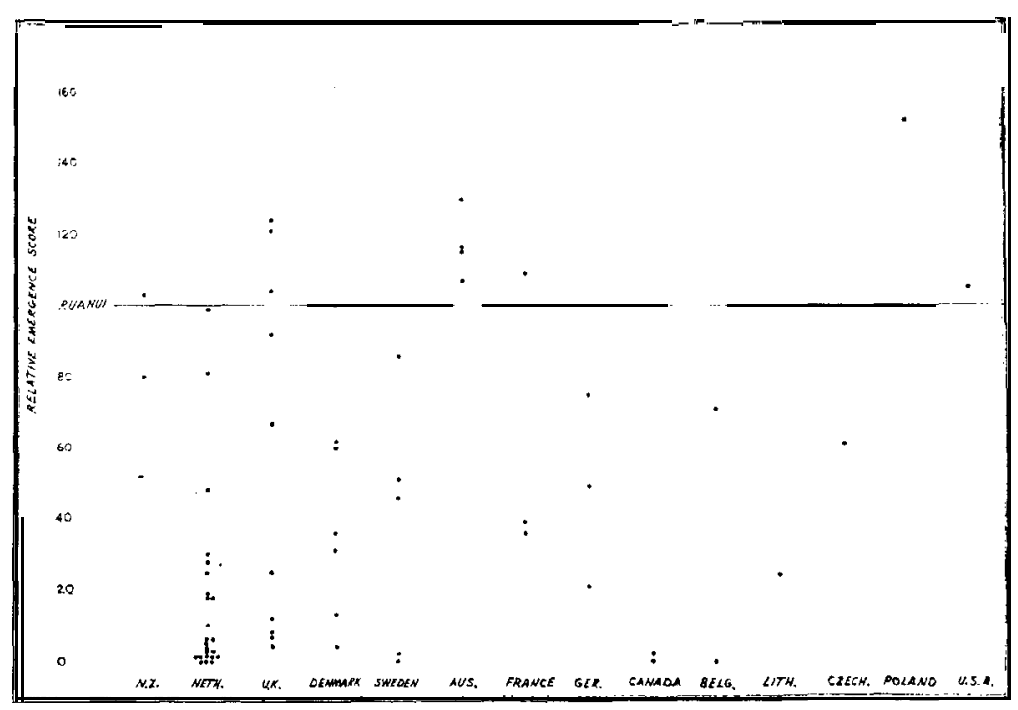

FIG. 3: Head emergence of overseas perennial ryegrasses, relative to 'Grasslands Ruanui'. (Low scores indicate late emergence.) 
RYEGRASS CULTIVARS

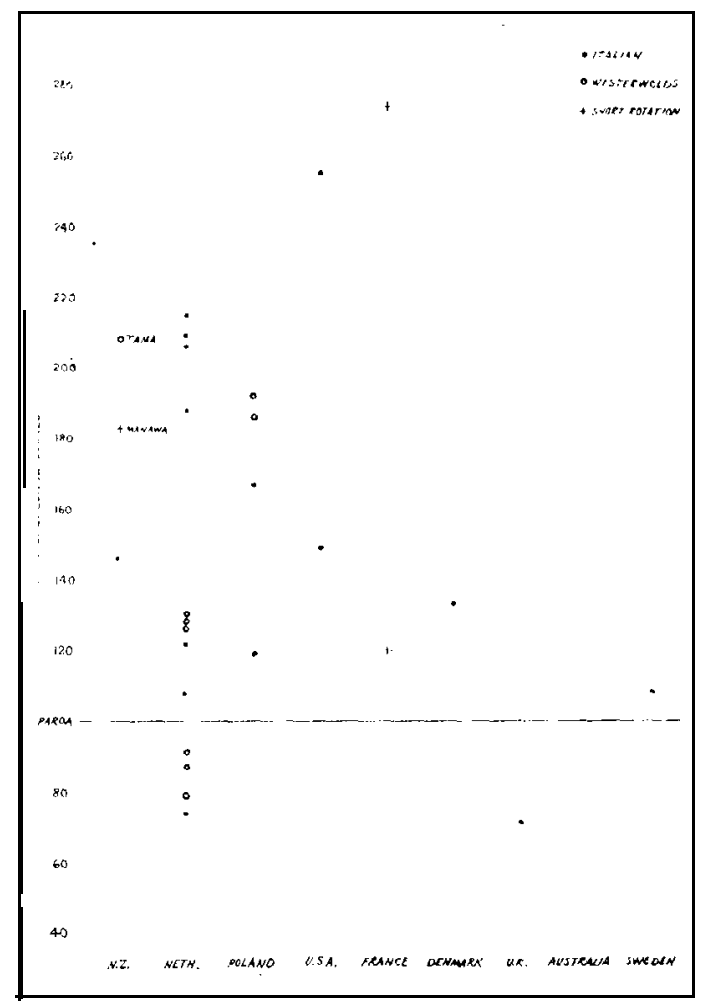

FIG. 4: Head emergence of overseas annual and short-rotation ryegrasses, relative to 'Grasslands Paroa' Italian ryegrass. (Low scores indicate late emergence.)

Most of the overseas Italian cultivars were considerably earlier heading than Paroa. However, the small sample of Westerwolds cultivars were later than 'Grasslands Tama', especially those from the Netherlands.

\section{DISCUSSION}

It has been reasonable for plant breeders to assume that cultivars bred in their own country would be more resistant to its diseases than would overseas cultivars. The present results show that while this may still hold for cultivars bred some decades ago, recently bred overseas cultivars are equally or more resistant than those bred for New Zealand conditions. This apparent resistance may of course decline with the appearance of 
new rust races and their build up into larger reservoirs of infection. However, it is also possible that overseas breeders are now selecting more intensively for disease resistance. This increasing interest in resistance also applies to New Zealand cultivars, and explains the greater resistance in the more recent cultivars, 'Grasslands Ariki' ryegrass and 'Grasslands Nui' perennial ryegrass. Current studies show that considerably more improvement can still be made.

A very wide range in heading dates occurs amongst the cultivars bred and marketed overseas. This relates to the greater climatic difference between summer and winter, which increases the divergence between pasture management for conservation (requiring early growing and early heading) and management for late grazing pasture (benefiting from late heading cultivars) . Generally, New Zealand has a less extreme difference between summer and winter growth (Cooper, 1969) so that the small emphasis placed on conservation can, to some extent, be met by the winter active annual and short-rotation ryegrasses. However, an attempt to breed a later heading perennial cultivar for southern New Zealand is currently being made. The problem that late heading cultivars in the seed production areas of this country tend to be low in seed yield (unpublished observations) will almost certainly be encountered.

\section{ACKNOWLEDGEMENTS}

We thank those past and present officers of Grasslands Division whose data have been included in this paper.

\section{REFERENCES}

Cooper; J., 1969. Occ. Symp. Br. Grussld Soc., 5: 5-13.

Corkill, L., 1956. Sheepfming A.: 47-51.

Lancashire, J. A.; Latch, G. C. M., 1966. N.Z. Il agric. Res., 9: 628.40. ; 1970. Ibid., 13: 279-86.

McLeod, C. C., 1974. Proc. N.Z. Grussld Ass., 35: 211-8.

Rumball, W.; Armstrong, C. S., 1974. Ibid., 36: 97-104. 